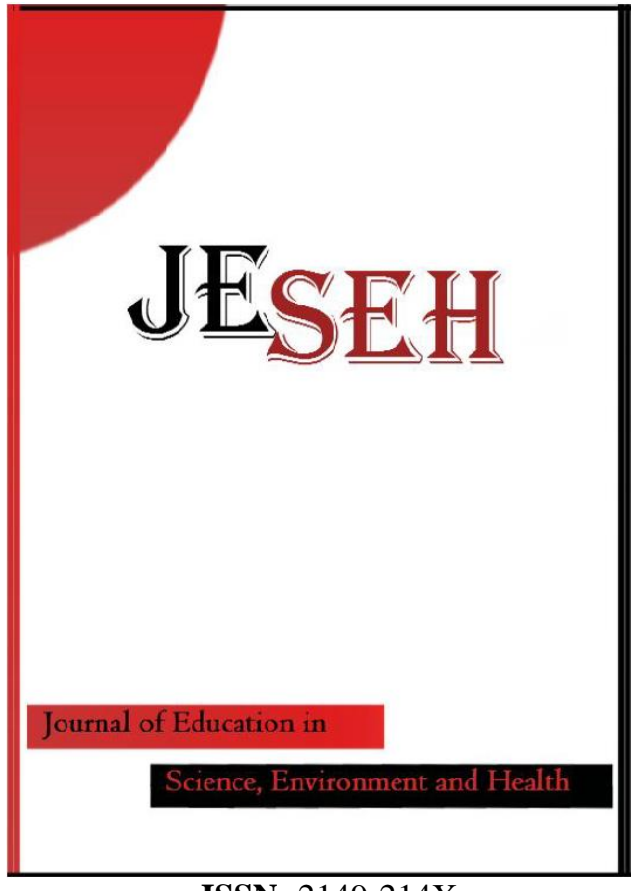

ISSN: $2149-214 \mathrm{X}$

\section{Journal of Education in Science, Environment and Health}

www.jeseh.net

Mentoring: Helping Youth Make a Difference in STEM

\section{Angelia Reid-Griffin}

University of North Carolina

To cite this article:

Reid-Griffin, A. (2019). Mentoring: Helping youth make a difference in STEM. Journal of Education in Science, Environment and Health (JESEH), 5(1), 1-11. DOI:10.21891/jeseh.478308

This article may be used for research, teaching, and private study purposes.

Any substantial or systematic reproduction, redistribution, reselling, loan, sub-licensing, systematic supply, or distribution in any form to anyone is expressly forbidden.

Authors alone are responsible for the contents of their articles. The journal owns the copyright of the articles.

The publisher shall not be liable for any loss, actions, claims, proceedings, demand, or costs or damages whatsoever or howsoever caused arising directly or indirectly in connection with or arising out of the use of the research material. 


\title{
Mentoring: Helping Youth Make a Difference in STEM
}

\author{
Angelia Reid-Griffin
}

\begin{tabular}{|c|c|}
\hline Article Info & Abstract \\
\hline History & \multirow{12}{*}{$\begin{array}{l}\text { Mentoring is a life-long approach to building positive, supportive relationships, } \\
\text { self-confidence and increasing academic performance. In this article, I present } \\
\text { how a college-based summer camp, designed to engage youth in increasing } \\
\text { interests in STEM, Healthcare, and Teacher education, by helping youth build } \\
\text { self-confidence and career interests through a Vertical Mentoring model. An } \\
\text { exploratory case study approach is used to gain insight into how the model } \\
\text { shaped youths' interactions in learning concepts in STEM. Middle school } \\
\text { participants completed a self-efficacy scale and career inventory of perceptions, } \\
\text { learning and academic interests. Middle school youth and mentors provided } \\
\text { insight on their attitudes, interests and overall satisfaction about the program } \\
\text { experiences. Findings interpreted based on the tenets of positive youth } \\
\text { development implemented and provides an anchor for additional mentoring } \\
\text { studies. Self-efficacy results indicated that students were motivated in utilizing } \\
\text { social resources and supports but rarely sought assistance from others. Drawing } \\
\text { from the interview responses from mentees and mentors, the Vertical mentoring } \\
\text { model afforded youth increased social interactions and opportunities in learning } \\
\text { about STEM concepts outside of their home and school settings. Thus, students } \\
\text { with no interest in STEM prior to the college-based camp did benefit positively } \\
\text { from the STEM mentoring opportunity. }\end{array}$} \\
\hline $\begin{array}{l}\text { Received: } \\
\text { 05 September } 2018\end{array}$ & \\
\hline $\begin{array}{l}\text { Accep } \\
10 \text { No }\end{array}$ & \\
\hline Keywords & \\
\hline Youth & \\
\hline & \\
\hline ГEM & \\
\hline 110 & \\
\hline Self-effic & \\
\hline & \\
\hline & \\
\hline & \\
\hline
\end{tabular}

\section{Introduction}

In terms of informal programs, one of the missing pieces in ensuring participants are motivated to pursue careers in STEM is mentoring. With still few longitudinal research studies of formal mentoring in informal settings (Center for Advancement of Informal Science Education (CAISE), 2016), the practice of mentoring has been known to positively influence the behaviors and career choices of many youth and adults. DuBois, Portillo, Rhodes, Silverthorn, and Valentine (2011) work on mentoring programs has noted that these programs are becoming more "commonplace in today's society" (p. 58) but the structure of these programs vary greatly. These mentoring programs often fail to provide youth with opportunities to reflect critically and to engage in discourse about their own experiences and understandings. Today's young adolescents need more opportunities to empower them to engage in challenges that are equitable and to develop their own personal identities (Association for Middle Level Education (AMLE), 2012). Adolescents can develop positive identities through mentoring interventions in informal programs, which can also provide supports that are also attentive to the young adolescents' culture, language and identity (AMLE, 2012; National Research Council, 2009). This paper shares how mentoring practices during a two-week summer program has benefitted youth by building supportive relationships and increasing interests in STEM, Healthcare, and Teacher education.

The objective of the paper is to explore how the college-based camp was able to utilize a mentoring platform, Vertical Mentoring to build the confidence among youth: middle school camp participants (mentees), high school student volunteers (mentors), and college student (mentors). Although mentoring is considered to be a standard practice in many afterschool and traditional school settings (Mentoring, 2010), by promoting the social and emotional success of youth, yet it appears to still lack research on its use in an informal environment such as a summer STEM/Health/Teacher Education camp. The critical questions the study south to answer: How does the mentoring opportunities in the Junior Seahawk program influences youths' confidence towards STEM concepts and careers aspirations? How does this experience influence self-efficacy of learners?

Successful mentoring methods such as the Big Brother Big Sisters (BBBS) have provided the platform for many after school or informal programs to create fun opportunities that guide and encourage youth to achieve academic success and develop career interests (Schwartz, Rhodes, Chan, \& Herrera, 2011). Mentoring supports the positive interactions between young people and an older experienced person as they work on tasks to develop career interests and build knowledge. Through this process of providing service to others it helps 
motivate young adolescents to become more engaged in experiences within their communities and to tackle difficult problems, such as individual differences, bullying, academics (Farber \& Bishop, 2018). The specified pairing of youths with experienced, caring volunteers trained to provide encouragement, education, and direction is essential for all mentoring programs to be effective (Schwartz et al., 2011).

Mentoring allows opportunities for comprehensive discussions among youth mentees and peers mentors about career concepts and values, while increasing social skills of both mentee and mentors as they interact with new people and places (Karcher, Davis, \& Powell, 2002). The summer camp targeted economically disadvantaged and underrepresented youth, in particular, to increase their ability to interact with STEM, Healthcare, and Teacher education professionals through this mentoring framework. These children have limited opportunities to attend specialized camps on the university's campuses and often perform meagerly in school subjects such as reading, math, and science. They also tend to have deficient behavior and disparities in their health care. Chaskin and Hawley (1994) revealed that many at-risk youth tend to isolate themselves from others at school and most likely lack a supportive environment to provide positive social and emotional support. Mentoring relationships that work allow for youth to develop trust and feel at ease talking and sharing their thoughts and goals with mentors. Programs that would enable young people to build confidence and are supportive of cognitive and social-emotional needs while helping the mentee develop their identity can lead to positive outcomes in academics, social, emotional, and career aspirations, especially in high need areas such as STEM, health care, and teacher education. Before sharing the findings, I begin with an overview of mentoring youth research and the youth mentoring model. I will explain the components of the vertical framework and how it was implemented. Highlighting our findings on how it aided young people to achieve positive learning outcomes in STEM, Health, and Teacher Education areas.

\section{Theory of Mentoring}

Mentoring is often viewed as a system to connect individuals in developing conversations of similar interests. It also is known to help in building social skills and fostering personal development during periods of transitions for individuals. The view of providing support to succeed in academics and social development is linked to the theory of developmental mentoring. This form of mentoring centered on the "connectedness and academic achievement" of youth significantly threatened by many of today's communities, which are becoming more isolated and less socially supportive as indicated Karcher et al. (2002).

In terms of levels of support, mentoring can be considered a multifaceted construct (Fullick-Jagiela, Verbos, \& Wiese, 2015). Support types such as career and psychosocial serve as the basic tenets to add in guiding and advising mentees in professional and personal life experiences. Positive youth development (PYD) approach has provided solid elements to identify practices of success and lack of success in influencing youth behaviors and potential career influences. The objectives of PYD aid in identifying impact this mentoring model plays in providing positive environment for youth development (Catalano, Berglund, Ryan, Lonczak, \& Hawkins, 2002, p. 5). Constructs of the objectives include: bonding, resilience, social competence, emotional competence, cognitive competence, behavioral competence, moral competence, self-determination, spirituality, self-efficacy, clear and positive identity, future belief, positive behavior, prosocial involvement and prosocial norms (p. 15).

The constructs of risk, resilience, and prevention-focused set the platform for Karcher's (2001) adolescent connectedness framework, which serves to retain children's motivation and interests in academic success and career pursuits. The social learning theory of change that focused on situated learning set forth by Lave and Wenger's (1991) concept of community of practice is also well suited to address the social and personal transformations of knowledge that occurs between mentees and mentors. The positive supportive relationship is framed on the exchange of ideas and sharing of experiences. This idea places children in a context where they can not only interact with a problem but also collaborate with novices (peers) and experts (mentors), while engaging in a socially supportive community of practice. This practice can ultimately lead to a unique mentoring environment that offers a sense of the cultural norms that enable social and emotional development of youth. The development of the Vertical Mentoring Model (Reid-Griffin, 2015) used in this program specifically addresses the nature of the supportive relationships within each mentoring level.

\section{Youth Mentoring Model}

Before the development of the Vertical Mentoring Model (Reid-Griffin, 2015) used in this research study, the Rhodes' Youth Mentoring Model (2004) was examined to help identify some core aspects of building and 
supporting mentoring relationships among participants in this enrichment summer program. Rhodes' model (2004) is conceptually based on the interactions of children and adolescents with adult mentors as it influences three areas of development: social, emotional, cognitive and identity. The design of the model situated around the theory of social interactions and the basic tenets of child and adolescent development: social, cognitive and identify development. The mentor has the crucial role of encouraging children/mentees so that they can "acquire and refine new thinking skills while becoming more receptive to mentors' values, advice, and perspectives" (Rhodes \& Dubois, 2008, pg. 256). In addition to engaging in these social development experiences, they are also able to construct their own identities. Building on the similar constructs of the Rhodes model (2004), the Vertical Mentoring Model (Reid-Griffin, 2015) is comprised of three-tiered stages that support cognitive development by providing opportunities for mentees to gain a sense of their current and future identity development. The design of this model allows for the social development among adult mentors who are a part of the post-secondary STEM, Health, and education programs to engage in mentoring relationships with career professionals and college faculty. The stages of the model that address youth mentoring [Level 1- Middle school students \& Level 2-High school students] focus on relationship development, cognitive growth and identity as it relates to their career aspirations and current interests. The conceptual framework, Collaborative Actions of Community by Erdogan and Stuessy (2015) helped in framing the stages of the Vertical Mentoring model (Figure 1) and defining the roles of the key players in this mentoring environment.

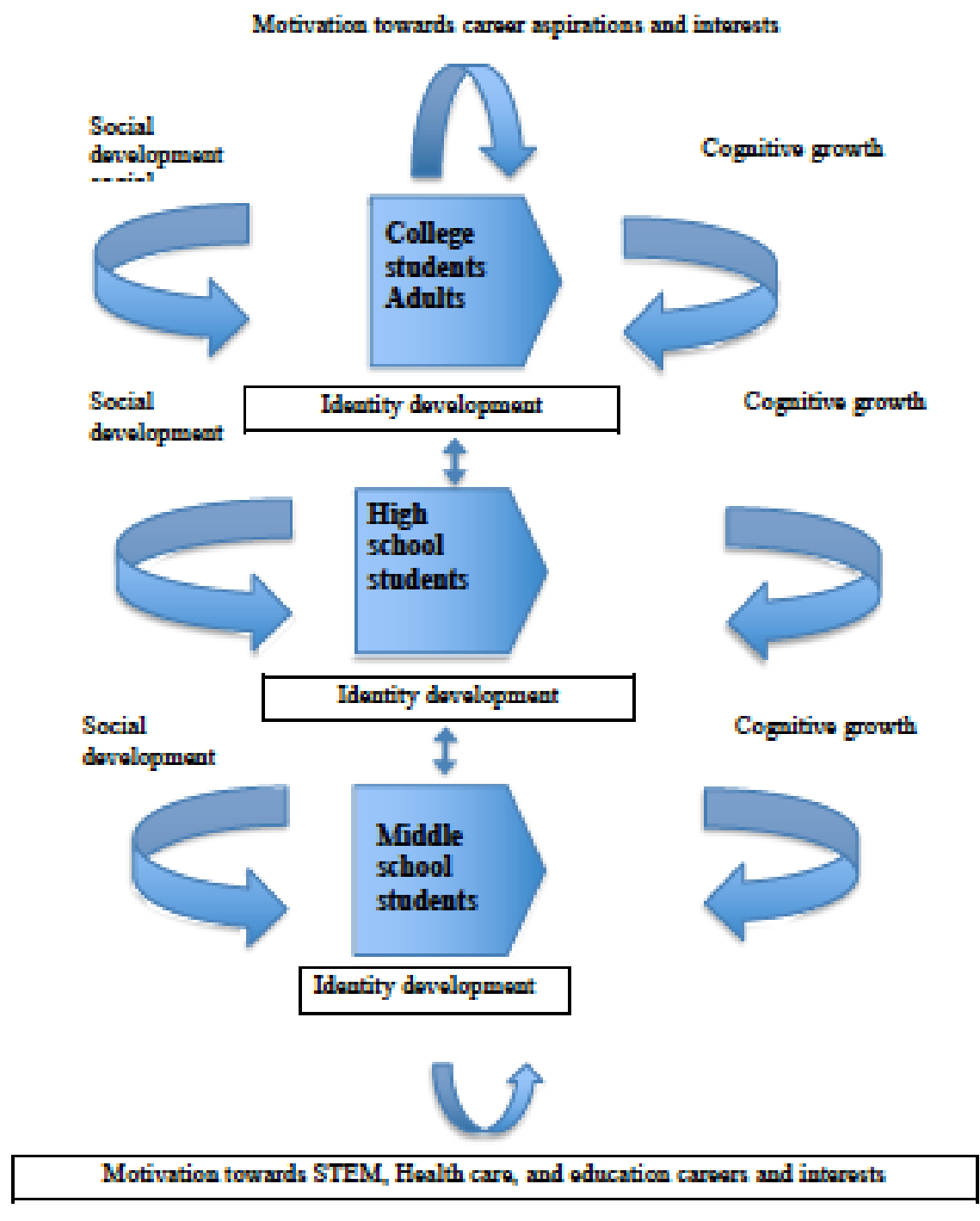

Figure 1. Vertical Mentoring model (Reid-Griffin, 2015) provides a platform for youth and adult mentoring targeting social, cognitive, and identity development 
The structure of the model starts with middle school students being mentored by their peers, high school students, and college students working with the summer program as STEM, Health or teacher education experts. Then at the next level, mentoring takes place among high school students, teenagers by college students, adults working with the program, and volunteer adult community mentors. The last level of mentoring occurs between the college students and adult volunteers with the program by instructional camp staff, university STEM, Health and education faculty and community professionals in these career fields. The dynamic features of the model provide for continued improvement in the areas of social and identity development as well as cognitive growth for both mentee and mentors.

This vertical structure for mentoring allows for the fostering of success among participants in the program as they engage in real-world activities in STEM, Health, and education. Motivation is also heightened with this model as students and adults can gain positive self-efficacy and confidence as they have interactions with a broad range of experts in STEM. As Monk, Baustian, Saari, Welsh, D'Elia, Powers, Gaston, and Francis (2014) indicated from their work with mentors the diversity of instructors involved in this model allow all students and adults feel a sense of giving back to the community and leads to "improved teaching, mentoring, and communication skills" (pg. 394). In this paper, the author describes work with using this Vertical Mentoring approach (Reid-Griffin, 2015) with middle school students, high school students and college students during a college-based summer program in STEM, Health, and Teacher education. Exploring how to get the students more engaged and interested in these careers as they became self-motivated and invested in program outcomes. Through the mentoring relationships, the author seeks to provide opportunities for youth to practice communication skills without feeling embarrassed and formal presentation experiences. Informal programs that include mentoring opportunities, such as the Junior Seahawk Academy, can transform students' perceptions and interests in these areas as well as provide monitoring of their academic progress.

\section{Context}

The Junior Seahawk Academy program has been in operation since 2003. The program provides a platform for middle school children to attend a college campus and learn from college faculty and students about STEM related fields. The program was revised to provide opportunities for former participants, rising sophomores and older high school students, to continue their interests in these fields and share their knowledge and academic experiences with younger participants. The expansion of the mentoring practice now includes college students interested in STEM areas and other adults in the community. The program took place each summer for 2 weeks from 8:30am-12:30pm. The high school students, college students and adult mentors participated in a 1-day training to prepare them for the program activities and reviewing mentoring procedures.

Throughout the week of the program, mentors were assigned to work with 1-3 middle school campers by engaging in conversations about career interests, hobbies and activities for the program. Typical day included students meeting together in the morning for group activity and then moving to their assigned grade level group. Each grade level group had a full time certified middle school instructor along with 3-4 high school or college mentors to assist. Program staff had backgrounds in STEM education and they taught one focus area of the camp to the students. The curriculum was developed by each individual teacher based on the camps' theme for the summer. For this summer's session theme, "Living in the Port City" students worked on activities to educate them on opportunities in the community related to STEM. After completing instructional activities, mentors met with their students and engaged in practices described by PYD constructs of bonding, resilience, social competence, emotional competence, cognitive competence, behavioral competence, moral competence, self-determination, self-efficacy, clear and positive identity, future belief, positive behavior, prosocial involvement and prosocial norms (Catalano, Berglund Ryan, Lonczak, \& Hawkins, 2002, p. 5).

The youth, who participated in the program as campers or volunteers or mentors, were from a diverse background as the demographics of the community has a wide array of ethnic and socioeconomic backgrounds. The region has a distinct demographic and economic composition creates unique challenges for local families and educators. Here, affluent gated subdivisions and beach resorts are flanked by both impoverished rural communities and urban areas with alarming levels of poverty and crime rates that rival those of much larger cities. Based on social capital, a notion developed by Coleman (1988) to describe the social structures within one's community, individuals relied on these structures to create resources that are devoted to improving one's skills, behaviors and life chances (Furstenberg \& Hughes, 1995). Thus, while growing up mere miles from a prestigious state university, too many students find themselves worlds away from the possibilities that higher education offers. This program offered student gains in social capital through knowledge of college programs, career opportunities in STEM and social networking with abilities to ask mentors for accurate advice. The 
learning opportunities in STEM career pathways also provided transformative effects on how participating youth achieve their goals and develop a sense of belonging. This opportunity creates meaningful connections that are centered on three constructs: communication, trust and effort. In addition to empowering youth in their own development but in that of their peers through mentoring. In the next 3-5 years the author hopes to see an increase in the test scores of camp participants and more interest in STEM and seeking higher education by all student participants.

\section{Method}

This research takes on an exploratory case study approach to gain insight into how the Vertical Mentoring model might affect the youth interactions in learning about STEM concepts, health and teacher education (Stake, 1995). Using both qualitative and quantitative measures to provide a descriptive approach of how this form of mentoring added to an area of research where little has been conducted. The study sought to answer the following research questions:

1) How do the mentoring opportunities in the Junior Seahawk program influence youths' confidence towards STEM concepts and careers aspirations?

2) How does this experience influence self-efficacy of learners?

The setting of the Junior Seahawk Academy was on the campus of a regional university in the southeastern region of North Carolina. The participants of this program and study comprised 50 middle school students. There were seven high school student mentors, five college student mentors and eight adult mentors who participated in the study. The middle school and high school students recruited from three local school districts in southeastern North Carolina. The schools are known to have higher populations of minority ethnic students, a significant number of students receiving federal assistance for lunch (free/reduced lunch) and are a part of populations that are largely underrepresented in STEM, Health, and teacher education careers.

The self-efficacy scale developed by Bandura (2006) was administered to the middle school students during the first day of the college-based camp in a large classroom setting. They were asked to complete the instrument fully to the best of their ability as a measure for research to explore their values toward learning during this experience. This instrument was used only with the middle school camp participants and selected because of its validity (Bandura, 2006). The instrument included a scale range of 0-100 with indicators for the following areas for self-efficacy: 1) Enlisting Social Resources; 2) Academic Achievement; 3) Self-Regulated Learning; 4) SelfAssertiveness; and 5) Enlisting Parental and Community Support.

During the last week of the summer program, randomly select middle school students $(n=7)$ were asked to participate in focus group session about their learning gains in the areas of STEM, Health, and Education. The students were provided time also to share what they liked and did not like about the program, including their thoughts on the mentoring sessions. The mentors for the summer program, high school $(n=7)$ and college $(n=4)$ were also asked to discuss their thoughts on this experience. They shared how their role as mentors influenced their careers interests and shared comments about mentoring work with the younger students. The overarching themes targeted by the mentoring model is presented in Table 1.

Table 1. Mentoring themes

\begin{tabular}{|c|c|}
\hline \multicolumn{2}{|l|}{ Mentoring Themes } \\
\hline Social development & - $\quad$ Peer interactions/Social interactions \\
\hline Cognitive development & $\begin{array}{l}\text { - Content knowledge confidence } \\
\text { - Skill-set knowledge confidence }\end{array}$ \\
\hline Identity development & $\begin{array}{l}\text { - } \quad \text { Self confidence } \\
\text { - } \quad \text { Leadership }\end{array}$ \\
\hline
\end{tabular}

At the conclusion of the summer camp, a program evaluation survey was distributed to all mentors (high school students, college students, and teaching staff/adults). The electronic survey instrument comprised 21 questions about the program's implementation of mentoring. The survey was developed author and administered on a 
secure survey management server maintained at the college. A small percentage of the mentors completed the electronic survey $(n=5)$, which was then subsequently analyzed in detail.

The data were analyzed using an exploratory mixed method approach in addressing the implementation of mentoring with the Junior Seahawk Academy program. There were additional qualitative methods used to understand students' perspectives towards the mentoring activities. Behavior observation recordings of mentor/mentee interactions during mentoring sessions and focus group interviews were completed in creating the triangulation strategy for this mixed method study (Creswell, 2003). The additional analysis involved using coding schemes to classify interviews and observation recordings concerning the effects of mentoring towards confidence and careers aspirations.

The focus group interviews with the middle school participants in the Junior Seahawk program took place on the last day of the half-day camp program. Twelve of the 50 participants $(n=12)$ were randomly selected by the researcher to participate in the focus group interview. All of the mentors $(n=20)$ also participated in a separate focus group interview to gauge their thoughts about the program and mentoring interventions used. They were asked questions related to their demographics, such as how they learned about the program, career interests; learning experiences in STEM/Health/Teacher Education and their opinions about the program activities and future events.

\section{Results and Discussion}

Analysis of survey and interview data are presented in two stages to reflect the questions that were used to guide the research. The data suggested that participants felt positive about the program's learning experiences in its ability to prepare them for a career in STEM, Healthcare, and Teacher education areas. Regarding how they learned about the program, 11 middle school participants indicated a family member mentioned the program to them and recommended that they participate. Only 1 of the middle school participants said they received the recruitment flyer at a school event. During the focus group interview conducted with the students several selected careers in STEM related field. Some of the careers mentioned were biomedical engineering, marine field, dentistry, game designing, pediatric surgeon, teaching, sports medicine and software engineer. Throughout the week they were engaged in presentations by a dentist, computer engineer, nursing professor and teaching professor. As the students shared their career interests one commented, "I changed my mind when we talked with the dentist. I didn't know what I want to be until they came and talked to us. I plan to be a dentist.”

The middle school participants' comments about learning gains in STEM, Health and Teacher Education after participating the program were mostly positive $(98 \%)$. Some of the children indicated the influence of their previous experiences such as their middle school, family and their roles on a science team during the school year.

Other children mentioned how this particular camp experience influenced their learning of the STEM and Health topics. A few of the comments were as follows: "it was fun, I learned about cardio, Spheros, and teaching"; "I learned STEM through my robotics and design \& modeling classes"; "I learned a lot about different ways to do science and math"; "STEM from school, healthy living, and my sister is working on her Masters in the Education school." There were some students (2\%) that were not happy about having to attend the program as they indicated, "mom made me come" during the focus group session and program survey. For the focus group sessions with middle school students and mentors, many of the comments revealed positive learning gains from the program.

Mentees (Middle school students):

- I should try new things, be cool and the ability to remake project idea

- learned a lot about different ways to do science and math

- Everything involves science

- ....you have to be focused, follow directions...planning ahead

- Always try

- There is more to engineering than the design

- Helping with project ideas

- Completing worksheets 
Mentors (high school/college students):

- Helped with making sure materials for the sessions were distributed

- Making sure students were on task and engaged

- Went on field trips

- I also helped with some experiments and getting them ready for the showcase at the end of the camp

The final comments from the mentors during the focus group session revealed that although the overall mentoring experience provided the participants good learning gains and opportunities to share their knowledge, there were limitations in the research. This included the amount of time students participated in program as well as the length of the mentoring session with students. All of the mentors indicated that the amount of time they were able to spend with the campers for mentoring was not enough. Many noted that much of the mentoring occurred as they traveled with students during STEM field experiences. Additional comments from mentors during focus group interview session conducted at the end of the camp session.

Student Comment A (high school): The aspect of the program that I liked was working with the kids and doing a whole bunch of different activities. I might be willing to participate again, depending on if I have the time.....

Student Comment B (high school): I would be willing to participate in this again because I could learn different skills I need for college and high school. The aspect of the program that I liked was the oneon-one teaching. And the people coming there to teach the kids different things about life and careers and college and everything.

Student Comment C (college): One aspect of the program I really liked was working with the kids, working with the....and the other little robots. And I would consider taking a career in STEM, like engineering, thanks to this program.

\section{Data Analysis}

The results indicated overall satisfaction with the program and activities from middle school participants who fully completed the Self-Efficacy scale complete $(\mathrm{N}=29)$. Due to timing of scheduled activities, other campers were not able to complete the scale, so their responses were not included in the data analysis and findings. The results displayed in Table 2, Table 3 and Table 4 present the response mean and standard deviation (SD) for each scale item. The Cronbach's alpha was .965 indicating scale reliability. The findings offered insight on students' satisfaction and perceived self-efficacy with Junior Seahawk program. Based on the middle school participants responses to the scale the standard deviations (SD) ranged from 28.00 to 43.00 indicating strong correlation of data around the mean responses to the scale items. In addressing the research question about the influences of this experience on students' self-efficacy the responses from the scale were modest for the scale items for "enlisting social resources", "academic achievement", "self-regulated learning", "leisure time/extracurricular activities", "meeting others' expectations", "social self-efficacy", "self-assertiveness" and "parental/community support." While not all students completed the scale they provided some feedback on their satisfaction with the program and mentors on an end of the program evaluation completed on the final day of the camp.

Based on the responses from the scale there was a moderate influence of others for support according to the instrument. The mean for enlisting social resources ranged from 53-61. The highest mean value (61.4) was for the statement receiving help from teachers while seeking peer help was the lowest mean at 53. In seeking support from other adults and peers with social problems, the mean score was roughly the same at 54. See Table 2 for a summary of response for the Social Resources and Parental and Community Support sections of the Bandura (2006) instrument. The part of the scale addressing Parental and Community Support had mean scores ranging from 40-74. Participants indicated a more significant rating for seeking help from parents or guardians with problems. The lowest mean score was seeking help from people outside of school reporting the limitation in participants' social interactions outside of their home and school environments. Building on mentoring methods with community supporters and volunteers in follow up program sessions can lead to participants' perceptions of social interactions being greater and occurring more frequently. 
Table 2: Summary of social resources \&parental and community support responses

\begin{tabular}{lll}
\hline & M & SD \\
\hline Social Resources & 61.4 & 34.0 \\
\hline Get teachers to help me & 52.8 & 38.6 \\
Get another student to help me & 54.5 & 41.8 \\
Get adults to help me & 54.1 & 40.2 \\
Get a friend to help me & & \\
\hline Parental \& Community Support & 74.5 & 37.9 \\
\hline Get my parent(s)/guardian(s) to help me & 48.3 & 43.9 \\
Get my siblings or other family members to help me & 55.2 & 39.5 \\
Get my parent(s)/guardian(s) to take part in school activities & 40.3 & 40.8 \\
Get people outside the school to take an interest in my school & 40.3
\end{tabular}

Note: As shown in the table the response percentages for question items and corresponding item Mean (M) and Standard Deviation (SD). N= 29. Scale survey was as following: 0=Not at all 10203040 50=Moderately 6070 8090 100=All the time

For the Junior Seahawk Academy program, the mentoring model provided opportunities for all participants, middle school students, high school students, and college students to benefit positively from the effects of mentoring on confidence towards STEM concepts and career aspirations. Although the mentoring model may not allow for all mentoring encounters to influence self-efficacy of learners, it did foster a sense of community, preparedness, and career readiness in STEM, Health, and Teacher education areas. In Tables 3 and 4, summary responses on Self-Efficacy indicated students were moderately confident and motivated in these response areas. The standard deviation ranged from 28 to 42 .

Table 3. Summary of self-efficacy responses

\begin{tabular}{lll}
\hline & M & SD \\
\hline Self-Assertive Efficacy & & \\
\hline Express my opinions when other classmates disagree with me & 65.2 & 40.9 \\
Stand up for myself when I feel I am being treated unfairly & 79.3 & 34.3 \\
Get others to stop annoying me or hurting my feelings & 77.2 & 38.1 \\
Stand firm to someone & 70.3 & 41.9 \\
\hline Self-efficacy for Academic Achievement & & \\
\hline Learning mathematics & 81.4 & 28.9 \\
Learning Algebra & 64.1 & 37.6 \\
Learning Science & 80.0 & 29.8 \\
Learning Biology & 69.3 & 34.3 \\
Reading, writing (Language arts) & 79.7 & 30.9 \\
Computers & 74.5 & 37.6 \\
Learning a foreign language & 54.8 & 39.9 \\
Learning social studies & 75.5 & 34.2 \\
Learn English grammar & 69.3 & 39.5 \\
\hline Self-efficacy for self- regulated learning & & \\
\hline Finish my assignments & 68.3 & 36.9 \\
Get myself to study when there are many other interesting things to do & 58.3 & 30.2 \\
Always concentrate on school subjects during class & 70.7 & 31.6 \\
Take good notes & 60.7 & 34.3 \\
Use the library to get information & 57.6 & 41.1 \\
Plan my schoolwork for the day & 53.4 & 39.1 \\
Organize my schoolwork & 65.5 & 37.7 \\
Remember information & 70.3 & 33.9 \\
Arrange a place to study without distractions & 55.5 & 36.3 \\
Get myself to do school work & 71.1 & 39.1 \\
\hline As shown in the table the response percentages for question
\end{tabular}

Note: As shown in the table the response percentages for question items and corresponding item Mean (M) and Standard Deviation (SD). Participant responses, $n=29$. 
Table 4. Summary of self-efficacy responses

\begin{tabular}{lcc}
\hline & M & SD \\
\hline Self-Efficacy for Leisure Time skills and extracurricular activities & & \\
\hline Learn sports skills well & 67.9 & 38.1 \\
Learn dance skills well & 47.9 & 40.0 \\
Learn music skills well & 54.1 & 39.8 \\
Work on the school newspaper & 42.4 & 39.2 \\
Serve in school government & 46.2 & 38.6 \\
Take part in school plays & 48.9 & 42.4 \\
Do regular physical education activities & 67.2 & 41.1 \\
Learn the skills needed for team sports & 64.5 & 42.4 \\
\hline Self-efficacy to meet others' expectations & & \\
\hline Live up to what my parents expect of me & 80.3 & 31.7 \\
Live up to what my teachers expect of me & 62.4 & 40.0 \\
Live up to what my peers expect of me & 61.4 & 40.1 \\
Live up to what I expect of myself & 88.6 & 28.0 \\
\hline Social Self-Efficacy & & \\
\hline Make and keep friends of the opposite sex & 73.1 & 37.8 \\
Make and keep friends of the same sex & 71.0 & 40.1 \\
Carry on conversations with others & 70.3 & 38.7 \\
Work well in a group & 71.7 & 33.4 \\
\hline
\end{tabular}

Note: As shown in the table the response percentages for question items and corresponding item Mean (M) and Standard Deviation (SD). Participant responses, $\mathrm{n}=29$.

In building on the importance of peer mentoring and community learning the Vertical Mentoring Model (ReidGriffin, 2015) provided a platform for students to gain confidence towards STEM content knowledge. It also allowed for students to work with others as they learned new skills and shared ideas without the feelings of intimidation. In terms of the constructs to indicate Positive Youth Development approach being an influence on the program, it was noted by their feedback and active engagement with mentors throughout the program sessions.

Furthermore, in the implementation of the mentoring model, we explored whether interactions and developmental changes caused participants and mentors to pursue additional after-school and summer STEMrelated activities. In developing a system for efficient mentoring as DuBois et al. (2011) researched, the idea of effective mentoring programs for youth, in general, is much easier to visualize than other approaches to youth service. Through mentoring, the problems or absence of role models was identified by the overall number of professionals in selected STEM and education roles, as well as the lack of diversity of these persons. Through this effort, we were able to determine how this mentoring approach is useful in motivating youth in careers related to STEM, Health, and Teacher education. The interactions provided through this mentoring framework allowed mentee and mentors to learn about STEM careers that are not as well-known by youth and practice new skills (Dworkin, Larson, \& Hansen, 2003). Participants of the Junior Seahawk Academy program indicated that they enjoyed the mentoring and collaborative opportunities provided. Excitedly, the program continues to expand the number of youth seeking to participate in programs.

Although mentor programs have served diverse populations of youths, including girls only programs, ethnic minorities, and various age groups, little is still known about processes and outcomes specific to these groups. The lack of research assessing gender, racial, and other group differences may, in part, be caused by limitations in the measurement of mentoring processes and constructs (Rhodes, Spencer, Keller, Liang, \& Noam, 2006). The research data lends further support on how the development of healthy relationships can occur among diverse populations of youth.

Anecdotally, one mentee cited specific benefits, as a racial minority in the program, he was able to experience those positive dynamics of mentoring by engaging in conversations and activities with guidance from a high school mentor.

Middle school participant: "I really enjoyed the mentoring piece and collaborating with other students who are also interested in science and math." 


\section{Conclusions and Next Steps}

In building on the importance of learning STEM and providing platforms for this learning to occur, programs that support hands-on learning and peer mentoring is what motivates young adolescents (Farber \& Bishop, 2018). The findings suggested that the implementation of this particular mentoring model is essential as well as planned curriculum/activities to support and foster the applicability of being in these fields. Community-based programs provide resources to foster youth engagement, involvement and leadership which is likely to help youth achieve personal interests and develop a sense of self efficacy and collective efficacy (Smith, Osgood, Caldwell, Hynes, \& Perkins, 2013). The Junior Seahawk Academy provides a shared community in which individuals, both youth and adults feel connected and supported as they learn and engage in STEM opportunities.

As Price, Kares, Segovia \& Loyd (2018) research on the importance of program staff in programming supported by PYD, this study was able to provide some insight to how a new approach to mentoring can offer youth the tools for positive behaviors and success in STEM. While future research is needed regarding a longitudinal study to gather data over a more extended time-span to strengthen findings on self-efficacy the study resulted in additional youth wishing to serve in mentoring roles for the programs' future sessions. Further work will continue in seeing how this model will help to provide additional insight into the gains for mentee and mentors after taking part in mentoring opportunities with youth. The findings provide an anchor in reporting how the Vertical Mentoring Model allows for valuable learning; high intrinsic motivation focused concentration on personal identity development, social and cognitive growth (Rhodes et al., 2006). Despite the limitations, this study represents an essential step in considering the pivotal role aspects of a mentoring model and how the relationships influence the benefits of youth pursuing careers in STEM, Health, and Teacher education.

\section{References}

Association for Middle Level Education. (2012). Middle level teacher preparation standards. Westerville, $\mathrm{OH}$.

Bandura, A. (2006). Guide for constructing self-efficacy scales. In Pajares, F. \&Urdan, T. (Eds.), Adolescence and education, Vol. 5: Self-efficacy beliefs of adolescents (pp. 307-337). Greenwich, CT: Information Age Publishers.

Catalano, R. F., Berglund, M. L., Ryan, J. A. M., Lonczak, H.S., \& Hawkins, J. D. (2002). Positive youth development in the United States: Research findings on evaluations positive youth development programs. Prevention \& Treatment, 5,1-111.

Center for Advancement of Informal Science Education, CAISE (2016). Mentoring in informal settings support youth identity development. Knowledge Base. Retrieved from http://www.informalscience.org/newsviews/mentoring-informal-settings-supports-youth-identity-development

Chaskin, R., \& Hawley, T. (1994). Youth and caring: Developing a field inquiry and practice. Chicago: Chapin Hall Center for Children.

Creswell, J. W. (2003). Research design: Qualitative, quantitative, and mixed methods approaches (2nd ed.). Thousand Oaks, CA: Sage.

Coleman, J. (1988). Social capital and schools. The Education Digest, 53(8), 6-9.

DuBois, D., Portillo, N., Rhodes, J., Silverthorn, N. \& Valentine, J. (2011). How effective are mentoring programs for youth? A systematic assessment of the evidence. Psychological Science in the Public Interest, 12 (2), 57-91. doi:10.1177/1529100611414806

Dworkin, J.B., Larson, R., \& Hansen, D. (2003). Adolescents' accounts of growth experiences in youth activities. Journal of Youth and Adolescence, 32, 17-26.

Erdogan, N. \& Stuessy, C. (2015). Modeling successful STEM high schools in the United States framework. International Journal of Education in Mathematics, Science and Technology, 3(1), 77-92.

Farber, K \& Bishop, P. (2018) Service Learning in the Middle Grades: Learning by Doing and Caring, RMLE Online, 41:2, 1-15, doi: 10.1080/19404476.2017.1415600

Furstenberg, F., \& Hughes, M. (1995). Social Capital and Successful Development among At-Risk Youth. Journal of Marriage and Family, 57(3), 580-592. doi:10.2307/353914

Karcher, M. (2001, August). Measuring adolescent connectedness: Four validation studies. Poster presented at the Annual Convention of the American Psychological Association, San Francisco, CA. Karcher, M., Davis, C., \& Powell, B. (2002). The effects of developmental mentoring on connectedness and academic achievement. School Community Journal, 12(2), 35-50.

Larson, R., Eccles, J., \& Gootman, J. A. (2004). Features of positive developmental settings. The Prevention Researcher, 11(2), 8-13.

Lave, J., \&Wenger, E. (1991). Situated Learning: Legitimate Peripheral Participation. Cambridge, MA: 
Cambridge University Press.

MENTOR, National Mentoring Partnership. (2010, April 16). What is mentoring? Retrieved from http://www.mentoring.org/mentors/about_mentoring

Monk, M., Baustian, M., Sarri, C., Welsh, S., D’Elia, C., Powers, J., Gaston, S., \& Francis, P. (2014). Environ Mentors: Mentoring At-Risk High School Students through University Partnerships. International Journal of Environmental and Science Education, 9 (4), 385-397. doi: 10.12973/ijese.2014.223a

National Research Council. (2009). Learning science in informal environments: people, places, and pursuits. Committee on Learning Science in Informal Environments. P. Bell, B. Lewenstein, A.W. Shouse, \& M.A. Feder (Eds.). Board on Science Education, Center for Education, Division of Behavior and Social Sciences and Education. Washington, DC: The National Academies Press. Retrieved from http://informalscience.org/research/ic-000-000-002-024/LSIE

Price, C. A., Kares, F., Segovia, G. \& Loyd, A. B. (2018). Staff matter: Gender differences in STEM career interest development in adolescent youth. Applied Developmental Science. Doi: $10.1080 / 10888691.2017 .1398090$

Reid-Griffin, A. (2015). Vertical Mentoring Model. University of North Carolina, Wilmington, NC.

Rhodes, J. E. (2004). Stand by me: The risks and rewards of mentoring today's youth. Cambridge, MA: Harvard University Press.

Rhodes, J. E., \& DuBois, D. L. (2008). Mentoring relationships and programs for youth. Current Directions in Psychological Science, 17, 254-258. doi:10.1111/j.1467-8721.2008.00585.

Rhodes, J., Spencer, R., Keller, T., Liang, B. \& Noam, G. (2006). A model for the influence of mentoring relationships on youth development. Journal of Community Psychology. 34, 691 - 707. doi: $10.1002 /$ jcop. 20124.

Schwartz, S., Rhodes, J., Chan, C., \& Herrera, C. (2011). The impact of school-based mentoring on youths with different relational profiles. Developmental Psychology, 47(2), 450-462.doi: 10.1037/a0021379.

Smith, E., Osgood, D.W., Caldwell, L., Hynes, K., \& Perkins, D. (2013). Measuring collective efficacy among children in community-based afterschool programs: Exploring pathways toward prevention and positive youth development. American Journal of Community Psychology 52, 27-40. doi: 10.1007/s10464-013-9574-6.

Stake, R.E. (1995). The art of case study research. Thousand Oaks, CA: Sage.

\section{Author Information}

Angelia Reid-Griffin

University of North Carolina Wilmington

601 South College Road, Wilmington, NC 28403

USA

Contact e-mail: reidgriffina@uncw.edu 